\title{
Rifting processes and ice-flow modulation observed on Mertz Glacier, East Antarctica
}

\author{
L. LESCARMONTIER, ${ }^{1,2}$ B. LEGRESY, ${ }^{4,3,2}$ N.W. YOUNG, ${ }^{5,3}$ R. COLEMAN, ${ }^{6,3}$ \\ L. TESTUT, ${ }^{2}$ C. MAYET, ${ }^{2}$ P. LACROIX ${ }^{7}$ \\ ${ }^{1}$ Research School of Earth Sciences, The Australian National University, Canberra, Australian Capital Territory, Australia \\ ${ }^{2}$ LEGOS (CNRS-CNES-UPS-IRD), Toulouse, France \\ ${ }^{3}$ Antarctic Climate \& Ecosystems Cooperative Research Centre, University of Tasmania, Hobart, Tasmania, Australia \\ ${ }^{4}$ CSIRO Oceans and Atmosphere Flagship, Hobart, Tasmania, Australia \\ ${ }^{5}$ Australian Antarctic Division, Kingston, Tasmania, Australia \\ ${ }^{6}$ Institute for Marine and Antarctic Studies, University of Tasmania, Hobart, Tasmania, Australia \\ ${ }^{7}$ Institut des Sciences de la Terre (ISTerre), CNRS/IRD, Université de Grenoble, Grenoble, France \\ Correspondence: L. Lescarmontier <lydie.lescarmontier@gmail.com>
}

\begin{abstract}
We investigated the evolution of two major rifts cutting across Mertz Glacier Tongue, East Antarctica, using a combination of satellite images and 60 day sets of GPS data from two stations deployed either side of the western rift in 2007. The eastern rift began to open in the early 1990s, and the western rift initiated in $\mathbf{2 0 0 2}$ in conjunction with the collision of a large iceberg with the tongue. Velocity time series derived from the 2007 GPS data exhibited strong variations at tidal periods modulated by sea-surface height and sea-surface slope and reproduced here with a conceptually simple model. We found that opening of the western rift in 2002 leads to a dramatic change in behavior of the tongue as the large range in velocity $\left(700-2400 \mathrm{~m} \mathrm{a}^{-1}\right)$ observed in 2000 was largely reduced (1075$1225 \mathrm{~m} \mathrm{a}^{-1}$ ) in 2007. Opening of the western rift decoupled the glacier from the transverse loading on the tongue driven by east-west tidal circulation. This loading previously induced time-varying lateral drag, which caused the large velocity range. Our results suggest changes in the mechanical behavior of an ice tongue impact the dynamics of the outlet glacier system and should be considered in longer-term mass-balance evaluations.
\end{abstract}

KEYWORDS: Antarctic glaciology, calving, crevasses, glacier flow, glacier mechanics

\section{INTRODUCTION}

In order to assess the mass budget of the Antarctic ice sheet into the future, the role of ice shelves in regulating the discharge from the ice sheet must be addressed, in addition to the processes that influence the evolution of those ice shelves and the associated ice streams (De Angelis and Skvarca, 2003; Rignot and others, 2004; Scambos and others, 2004). The development of rifts in ice tongues can have two consequences: calving of the ice tongue, or a change in the mechanical properties of the tongue such that it modifies how external forces influence the flow of the glacier. We use observations of Mertz Glacier and its ice tongue to explore this second topic.

Mertz Glacier is one of three main fast-flowing icestream and outlet glacier systems of the King George $\mathrm{V}$ Coast region of East Antarctica (Fig. 1), the others being Ninnis Glacier and the Cook Ice Shelf. The bathymetry of the continental shelf near Mertz Glacier is characterized by the presence of a deep valley running parallel to the coast, known as George $V$ Basin, where the water depth reaches 1000-1400 m. Mertz Glacier forms a floating ice tongue, which is contained in a fjord for the first $60 \mathrm{~km}$ of its length, and extends another $90 \mathrm{~km}$ out from the coastline. Icebergs typically ground in the shallow waters, around $300 \mathrm{~m}$ deep, over the continental shelf near Mertz Glacier Tongue. Southeast and east of the George V Basin, icebergs often ground near the coast and may cause calving of ice shelves due to impact with ice tongues. These icebergs may originate from local sources or from as far east as the Ross Sea.

Mertz Glacier Tongue calved an iceberg $\sim 75 \mathrm{~km}$ long and $\sim 35 \mathrm{~km}$ wide in February 2010, following the collision of iceberg B9B with the outer part of the tongue (Young and others, 2010). B9B originally calved from the Ross Ice Shelf in 1987, drifted across the Ross Sea, passing Cape Adare before heading west along the coast (Keys and Fowler, 1989) and reached an area to the east of Mertz Glacier in 1992. It was grounded there for 17 years before moving again in late 2009 and coming into contact with Mertz Glacier Tongue during early February 2010. At this time, Mertz Glacier Tongue was already weakened by the development of two large rifts: one on the western side, the other on the eastern side (Fig. 1). The two rifts were almost joined when $\mathrm{B} 9 \mathrm{~B}$ collided with the eastern flank of the ice tongue. No information exists about calving events on Mertz Glacier prior to the 2010 event. Frezzotti and others (1998) deduced, from the observation of the evolution of the ice tongue length, that at least one major calving event occurred between 1912 (when it was mapped by the Australasian Antarctic Expedition) and 1958 (mapped by a Soviet Antarctic expedition). Another calving event between 1958 and the present time is deduced in order to explain the size of the ice tongue prior to its calving in 2010, given the observed velocities.

There have been a number of studies of the processes that drive rift opening. For example, Holdsworth (1985) 


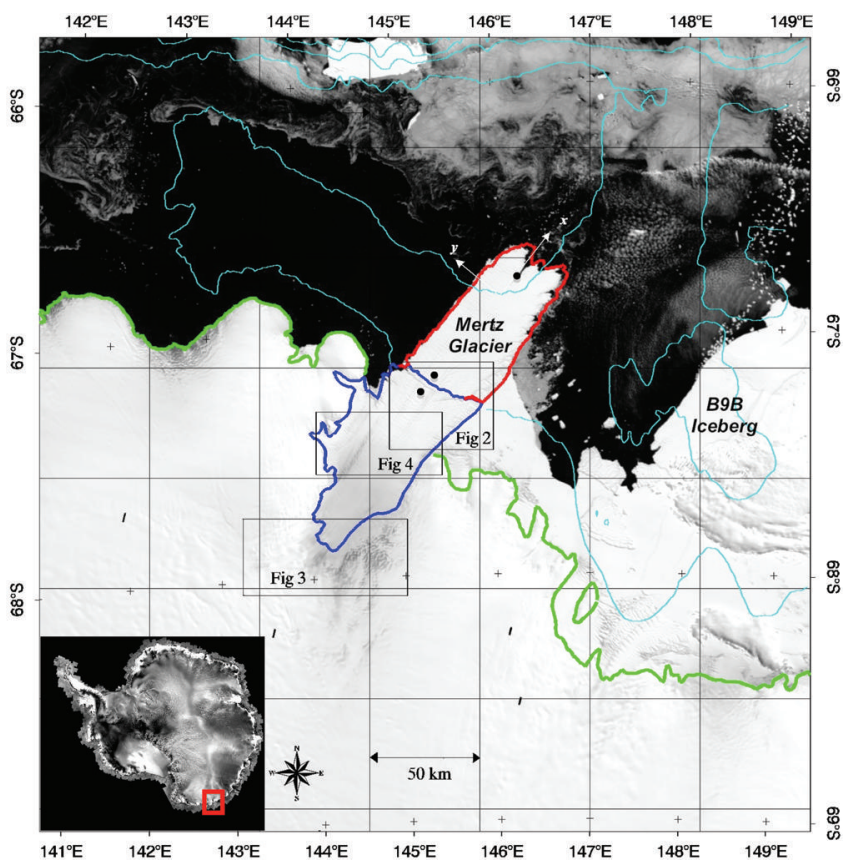

Fig. 1. MODIS (Moderate Resolution Imaging Spectroradiometer) image from 2006 of the Mertz Glacier area, projected in UTM with a $50 \mathrm{~km}$ spacing. The green curve corresponds to the coastline by Mayet and others (2013), updating the Mosaic of Antarctica coastline. The bathymetry appears in light blue with contours every $500 \mathrm{~m}$ depth. The boxes Fig 2, Fig 3 and Fig 4 correspond to the extents of those figures. The western and eastern rifts are in dark-blue and red respectively (see Fig. 2). They represent the limit of the Mertz Glacier iceberg, C28 (Young and others, 2010) which calved in February 2010. The outline of this iceberg appears in red and is shifted from the 2006 image (as a consequence of the glacier flow). The dark-blue contour marks the limit of the upstream part of Mertz Glacier. The black dots correspond to the locations of GPS 4 and GPS 5 (in the Fig 2 box) and the GPS used by Legresy and others (2004). C NASA Goddard Space Flight Center and US Geological Survey.

demonstrated that tidal currents are the main mechanical driver inducing fatigue failure of ice tongues. In the case of Mertz Glacier Tongue, we previously investigated the evolution of the main rift leading up to the calving that occurred in February 2010, using GPS measurements acquired during the November 2007 field program (Lescarmontier and others, 2012). Two months of data were collected at two GPS stations, GPS 4 and GPS 5 (Fig. 2), located on each side of the main (western) rift. From these measurements, Lescarmontier and others (2012) demonstrated the effect of ocean-forced vibrations on the main rift opening.

A second aspect of the evolution of ice shelves in relation to the ocean is the tidal modulation of the ice velocity. Anandakrishnan and others $(1994,1997)$ and Bindschadler and others (2003) established that tidal-scale variations occur in the movement of West Antarctic ice streams. Murray and others (2007) and Gudmundsson (2006, 2007) found tiderelated variations in the velocity of Rutford Ice Stream. Recently, Brunt and others (2010), King and others (2010, 2011), Gudmundsson (2011), Winberry and others (2011) and Makinson and others (2012) investigated the nature of tide-related variations in the velocity of the Ross, Larsen and Ronne ice shelves. The characteristics of these tide-related horizontal velocity variations range from stick-slip (Bindschadler and others, 2003) to more gradually modulated

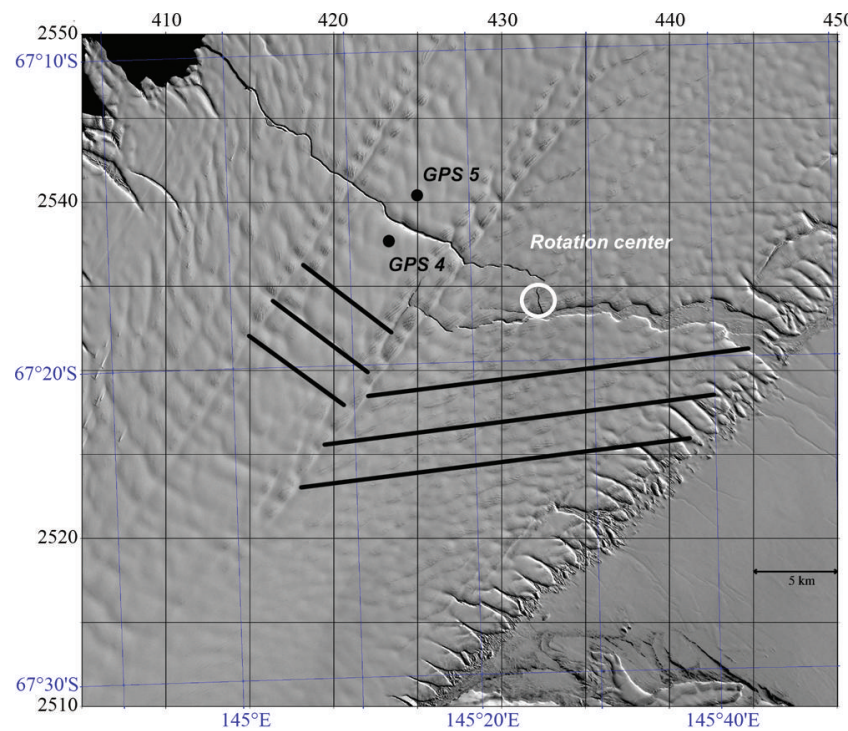

Fig. 2. Box 2 from Figure 1. Landsat 7 image of 2 February 2003 with $15 \mathrm{~m}$ pixel size. We observe on this image the two rifts located at the eastern and western side of the ice tongue and the position of GPS 4 and GPS 5 on each side of the main rift. The mean orientations of surface structures, which exhibit different behaviors on the two ice streams, are indicated with black lines. The features develop upstream of the grounding line orthogonal to the ice velocity vector ( $y$ vector, across-tongue). The western ice stream bends left as it crosses the grounding line into Mertz Glacier Tongue and retains the orthogonal orientation. However, on the southern stream, which bends to the east across the grounding line, the features become rotated anticlockwise with respect to the flow vector ( $x$, along-tongue) on Mertz Glacier Tongue. The projection is in UTM with a $5 \mathrm{~km}$ grid spacing. (C) Landsat 7 imagery courtesy of US Geological Survey.

velocities. Gudmundsson (2006) found strong fortnightly variations, in addition to the daily signals, in the movement of Rutford Ice Stream. This new observation led Gudmundsson (2007) to acknowledge the need for nonlinear mechanisms to explain the coupling between tides and ice flow. Analysis of the horizontal velocity of ice shelves showed links between the time variations of the sea-surface slope and those of ice velocity. Doake and others (2002) investigated the effect of currents upon the horizontal displacement of Brunt Ice Shelf, and Thomas (2007) suggested that tidal tilting of ice shelves may contribute to the back-pressure force, which in turn could affect the ice velocity feeding into ice shelves across the grounding zone. Furthermore, Makinson and others (2012) analyzed the response of the Ronne Ice Shelf to tidal circulation and found that its tidal tilting drives horizontal displacements and velocity oscillation with a maximum effect in the outer part of the ice shelf and decreasing to near zero at the grounding zone.

Concerning Mertz Glacier Tongue, Legresy and others (2004) focused on the influence of tides on the velocity using interferometric synthetic aperture radar (InSAR) analysis and 3 days of GPS measurements collected in two sequences within an overall time interval of 4 days in 2000. The in situ GPS station was placed near the front of the ice tongue. The GPS time series showed a velocity varying with time in phase with the direction of the modeled tidal circulation and the ice velocity, with a range in value between 1.9 and $6.8 \mathrm{md}^{-1}$. Their explanation was that when the ice tongue was pushed eastward, its advance 
rate was reduced by lateral drag along the eastern side of Mertz Glacier Tongue inside the fjord. When the tidal circulation was pushing the tongue westward the accumulated stress was released, allowing the ice tongue to advance rapidly. In addition, Mayet and others (2013) show that the dominant oceanic force comes from the (east-west) sea surface slope driven by the tidal circulation, and that the water pressure on the side of the tongue exerts only a small influence on its movement.

Using two 60 day sets of in situ GPS data, a barotropic ocean model (Toulouse Unstructured Grid Ocean Model (TUGO-M)), a basal drag based model developed by Gudmundsson (2007) and a set of satellite images, we investigate the impact of tidal circulation and sea-surface slope on both rift opening and ice velocity. We find a very significant change in how the tides influence the ice flow from the period observed by Legresy and others (2004) to the present study. We ascribe this change to the development of the two major rifts in Mertz Glacier Tongue between 2000 and 2007.

\section{DATA AND METHODS}

\subsection{GPS time series}

The GPS data from the CRAC-ICE (Collaborative Research project into Antarctic Calving and ICeberg Evolution) November 2007 field program were collected by two receivers (Topcon GB1000 with PGA1 antennas), deployed to each side of the main western rift of Mertz Glacier Tongue with a 30 s sampling interval. The GPS receivers recorded data over 60 days, from 15 November 2007 to 15 January 2008.

The data from both GPS 4 and GPS 5 receivers have been processed using the GINS-PPP software developed by the Centre National d'Etudes Spatiales, France (Marty and others, 2012). This software allows the use of a Precise Point Positioning kinematic methodology and solves for ambiguities as integer values (Blewitt, 2008). Such GPS data processing is usually achieved using a double-difference processing strategy. The new strategy provides an ideal way to process GPS data without the need for a reference or base station (i.e. relative positioning) and it still achieves a $2 \mathrm{~cm}$ accuracy (Lescarmontier and others, 2012).

The GPS positions were determined in Cartesian geocentric coordinates, in the ITRF2005 reference frame, taking into account the modeled solid earth and ocean tide loading displacements. Lescarmontier and others (2012) provide further details of the processing and the possible spurious signals remaining. We projected our solutions into a local orthogonal topocentric coordinate system $(x, y, z)$ with the $x$ axis defined as the along-tongue direction (defined as the velocity averaged over the whole observation period), $y$ to the left, across the tongue, and $z$ the local up direction (the local vertical, orthogonal to the $x$ and $y$ axes; Fig. 1). In the following we will use the terminology along-tongue for the $x$ direction and across-tongue for the $y$ direction.

\subsection{Satellite images}

We used imagery from Landsat 7 in panchromatic mode (15 m pixel size), SPOT 5 (Satellite Pour l'Observation de la Terre) in panchromatic mode (5 $\mathrm{m}$ pixel size), and European Remote-sensing Satellite (ERS-1 and ERS-2) synthetic aperture radar (SAR) images for both interferometric phase interpretation of the deformation and SAR amplitude images as a complement to the visible images. ERS images were processed with a $20 \mathrm{~m}$ pixel size. The images were then georeferenced and projected onto the Universal Transverse Mercator (UTM) zone 55S map reference system using World Geodetic System 1984 (WGS84) ellipsoid parameters.

The images used are from different time periods and were selected to illustrate a specific feature or change in that feature. However, selection of a particular date for an image to best highlight the phenomenon under discussion is limited by the availability of images that are of suitable quality (e.g. cloud conditions in most of the MODIS images are overcast so the surface is obscured). Concerning the SAR images, only one set of images, comprised of four pairs from ERS-1 and ERS-2 sufficient to produce two double-difference interferograms, were available over the entire time period. SPOT 5 images were ordered specifically for our study, and so start later on.

\subsection{Basal shear stress and sea surface slope based modeling}

In the following, we determine the contributions from the different drivers of modulation of the ice tongue velocity. For this, we adapt a model developed by Gudmundsson (2007) that allows the basal shear stress to vary with the tide. We assume that all the variation in velocity on the floating tongue (as measured by our GPS), which we ascribe to tidal modulation, equates to the variation in velocity of the inflow from the grounded portion of the glacier. The difference between the velocity at the grounding zone and at our GPS station is the increase in velocity along the tongue due to longitudinal extension of the ice in the tongue. Measurements by feature tracking in satellite images show this additional velocity contribution is $0.55 \mathrm{~m} \mathrm{~d}^{-1}$. The velocity variations across the grounding zone are thus transmitted to the floating part and to the rest of the ice tongue.

Gudmundsson (2007) implemented a model of icestream flow in which the basal shear stress was allowed to vary in conjunction with the tidal signal. With that model he was able to reproduce fortnightly variations in ice velocity of the type observed on Rutford Ice Stream. The two main assumptions used in that model are that:

1. within the ice, tidally induced stress perturbations are linearly related to tidal amplitude; and

2. deformation of till underlying the ice stream follows a nonlinear relationship between the shear stress and the rate of basal sliding velocity.

The basal sliding velocity is generally expected to be some function of basal shear stress (Clarke, 1987; Iverson and others, 1995; Truffer, 1999; Tulaczyk and others, 2000; Fischer and others, 2001; Tulaczyk, 2006), and the results from Gudmundsson (2007) reinforce that assumption.

Our model follows the formulation of Gudmundsson (2007), in which the basal shear stress is defined as

$$
\tau_{\mathrm{b}}(t)=\overline{\tau_{\mathrm{b}}}+\Delta \tau_{\mathrm{b}}(t)
$$

where $\overline{\tau_{\mathrm{b}}}$ is the mean basal shear stress and the tidally driven variation is given by

$$
\Delta \tau_{\mathrm{b}}(t)=K \rho_{\mathrm{w}} g h(t)
$$

where $\rho_{\mathrm{w}}$ is the density of sea water, $g$ the gravitational acceleration, $h(t)$ the height of the ocean tide varying with time, and $K$ is a site-dependent modeling parameter.

We introduce an additional component corresponding to a gravitational force induced by the effect of sea-surface 


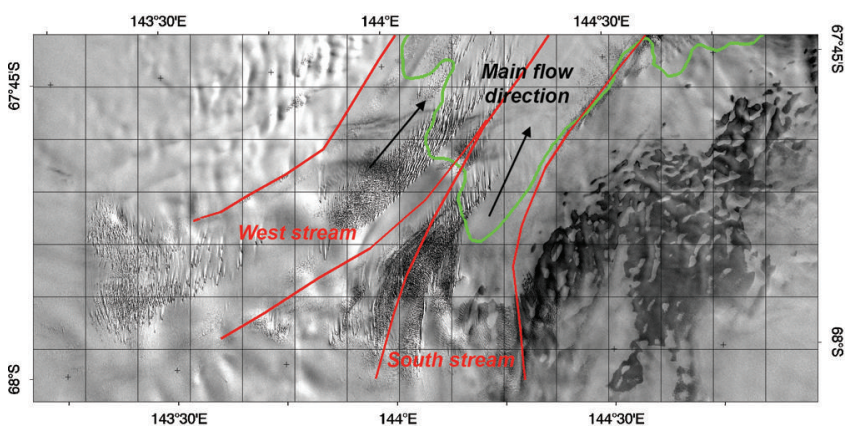

Fig. 3. Box 1 from Figure 1. SPOT 5 image of the grounding zone from 5 February 2008 with the location of the grounding line (green) and flowlines (red). The projection is in UTM with a $5 \mathrm{~km}$ grid spacing. The grounding line appears in green following the InSAR analysis of Poetzsch and others (2000). C CNES 2008/ Distribution Spot Image.

slope following Makinson and others (2012) and Mayet and others (2013), and we optimize the parameter values to match the situation on Mertz Glacier such that

$$
\Delta \tau_{s}(t)=K_{s} M g \frac{\sin \alpha}{S}
$$

where $K_{s}$ is a constant, $M$ is the mass of the ice tongue (here we estimate the volume using area from the imagery and thickness from radio-echo sounding to derive a value of $3200 \mathrm{Gt}), \alpha$ is the sea-surface slope in the along-tongue direction and $S$ is the cross-sectional area at the grounding line on which the force is acting (here we take an approximation of $S=5600 \mathrm{~m}^{2}$ as a simple geometric cross section based on our limited knowledge of ice thickness).

The basal shear stress can now be written, using Eqns (2) and (3), as

$$
\tau_{\mathrm{b}}(t)=\overline{\tau_{\mathrm{b}}}+K \rho_{\mathrm{w}} g h(t)+K_{s} M g \frac{\sin \alpha}{S}
$$

where $K$ and $K_{s}$ (constants) are the two site-dependent modeling parameters. In simple terms, the value of $K_{s}$ is expected to equal that for $K$, but there is considerable uncertainty in the value of $M$, as well as the actual effective cross section $S$. As a consequence, these parameters will take different values. In addition, the influence of the tidal height is not simply exerted as the normal load at the base, but will be the integral of variations in drag over various parts of the base and sides of the tongue. In the following, we adjust $K$ and $K_{s}$ by a least-squares parameter optimization.

The basal sliding velocity $u_{\mathrm{b}}$ is written as

$$
u_{\mathrm{b}}=C \tau_{\mathrm{b}}^{m}
$$

where $C$ and $m$ are modeling constants. This equation refers to Weertman's sliding law (Paterson, 1994). The total forward velocity is then assumed to be

$$
u_{\mathrm{s}}=u_{\mathrm{d}}+u_{\mathrm{b}}=\left(\frac{1}{r}+1\right) u_{\mathrm{b}}
$$

where $r=\frac{u_{\mathrm{b}}}{u_{\mathrm{d}}}$ is the slip ratio, i.e. the ratio between the mean sliding velocity $\left(u_{\mathrm{b}}\right)$ and the mean forward deformational velocity $\left(u_{\mathrm{d}}\right)$. We adopt values for the sliding exponent of $m=3$, and the basal sliding coefficient of $C=0.12 \times$ $10^{-3} \mathrm{~m} \mathrm{~d}^{-1} \mathrm{kPa}^{-m}$ from Paterson (1994), also determined as being the best-fitting values.

The main coefficients that remain to be determined are the slip ratio $r$, deduced from the ice surface slope, the mean surface velocity $u_{\mathrm{s}}$, the coefficients $K$ and $K_{s}$ for the time-varying components of the basal shear stress, and the mean basal shear stress $\overline{\tau_{\mathrm{b}}}$ (Gudmundsson, 2007 for explanations). The optimal values found for the various parameters (following the procedure of Gudmundsson, 2007) are slip ratio $r=107, \overline{\tau_{\mathrm{b}}}=26 \mathrm{kPa}, K=0.05$ and $K_{s}=0.07$. The values of $K$ and $K_{s}$ are similar, as expected before optimization. Sensitivity analysis and least-square optimizations are undertaken to fit the best parameter values, although no direct comparison with data from other ice streams is attempted.

\section{RESULTS}

\subsection{Initiation of rifting}

Two ice streams merge at about the grounding line to form Mertz Glacier Tongue. We refer to these as the west and south ice streams (Fig. 3). We derive their dimensions using SAR interferometry (Legresy and others, 2004), picking the shear limit as well as flowlines from a combination of repeated Envisat Advanced SAR images (red in Fig. 3). The southern ice stream is $10-15 \mathrm{~km}$ wide and the western stream is $13-14 \mathrm{~km}$ wide.

Figure 2 reveals surface features that exhibit different behaviors on the two ice streams. Transverse features oriented orthogonal to the ice velocity vector ( $y$-direction, across-tongue) develop on both ice streams, upstream of the grounding line. The western ice stream bends left as it crosses the grounding line into Mertz Glacier Tongue and retains the orthogonal orientation of the features all the way to Mertz Glacier Tongue front. By contrast, for the southern stream, which bends to the right across the grounding line into Mertz Glacier Tongue, the features become rotated anticlockwise with respect to the flow vector $(x$, alongtongue) on the glacier tongue.

In Figure 4, we present the SAR amplitude image (Fig. 4a) and two different sets of double-differenced interferograms (Fig. 4b and c), zoomed on the part of Mertz Glacier Tongue where it exits the fjord. We observe a sequence of lateral rifts (appearing at the edge of the ice stream) in the southeast margin of Mertz Glacier Tongue, which form where the ice stream exits the fjord ( $\mathrm{H}$ (hinge) zone in Fig. 4a). MacGregor and others (2012) hypothesize that rifting as appearing in Figure 4 is favored at the margins, which are expected to be rheologically weaker (Echelmeyer and others, 1994; MacAyeal and others, 1998; Khazendar and others, 2007) and to have numerous surface crevasses that may connect with basal crevasses, which form at the grounding line, to form margin rifts (Catania and others, 2006). The major eastern rift initiated in one of these margin rifts, and preferentially propagated along the transverse features that had initiated in the vicinity of the grounding zone. The major western rift developed in a similar fashion. Legresy and others (2004), when investigating the flexure of Mertz Glacier Tongue, showed that the outer part of the ice tongue bends about the hinge zone $(\mathrm{H}$ in Fig. 4a) as a result of its flexure, and that this flexure is driven by the ocean circulation.

In Figure $4 b$, we observe dense fringe patterns along the margin of the glacier tongue associated with the vertical tidal motion, and a broad set of fringes on the outer tongue indicative of the horizontal rotation of that part of the tongue about zone $\mathrm{H}$. In particular, we see fringe patterns over each of three transverse features (A, B, C in Fig. 4b) on the western 


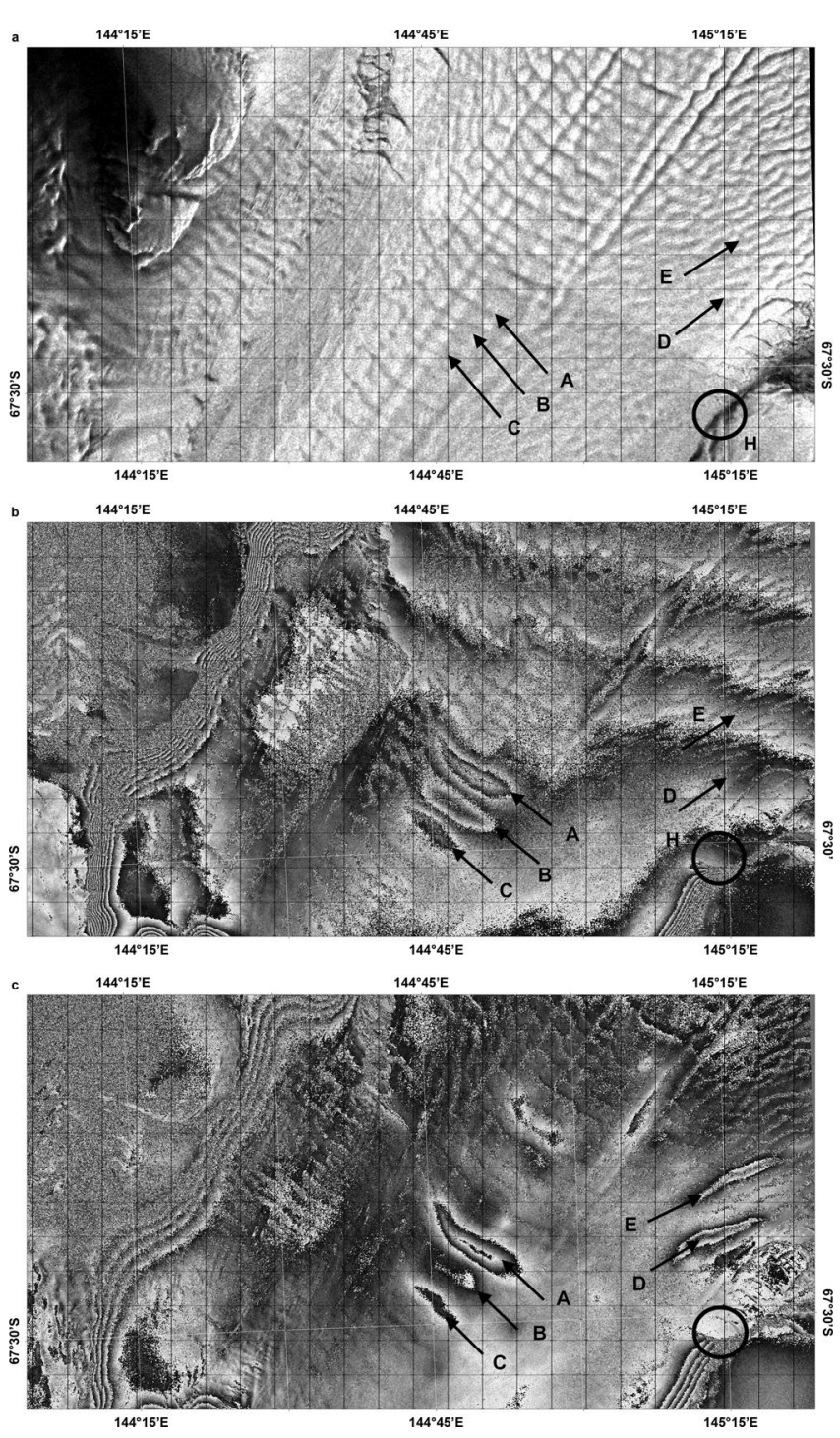

Fig. 4. Box 3 from Figure 1. Interferometric image from 1996 corresponding to the ERS SAR scenes of the stress zone on Mertz Glacier Tongue. (a) Amplitude and (b, c) phase. The projection is in UTM with a $2.5 \mathrm{~km}$ grid spacing. The images used to form these double-difference interferograms were acquired in April-May 1996. One fringe corresponds to $28 \mathrm{~mm}$ distance variation in the satellite line-of-sight (for details of the processing see Legresy and others, 2004). The circle surrounds the hinge point $(\mathrm{H})$ at the east of the glacier tongue. Arrows A, B and C point to the location of some of the crevasses at the site of the hinging point where the beam stress is maximum. Arrows D and E point to other crevasses forming on the eastern side of the ice tongue. SAR data CEuropean Space Agency 1996.

ice stream, which reveal differential deformation within these features. The fringe pattern is equivalent to a relative displacement of the order of $2 \mathrm{~cm}$ in the satellite line-of-sight vector. Similarly in Figure $4 c$, the different combination of tidal intervals results in fewer fringes from tidal vertical motion and an absence of horizontal rotation fringes. There, we see different patterns of deformation within features $A, B$ and $C$ and, in addition, we see differential deformation of transverse features $D$ and $E$ from the southern ice stream. As the ice tongue advances $\sim 1 \mathrm{kma}^{-1}$ in this area, the transverse crevasses will be advected with the flow and new crevasses will initiate, forming the typical features visible on Mertz Glacier Tongue.



Fig. 5. Evolution of the rift surface area from 1996 to 2009 calculated from Landsat 7 and SAR images. The red line corresponds to the area of the eastern rift, the blue line to the area of the western rift (Fig. 1), the green lines are the sum of both rift areas, and a linear regression of the total area is plotted. Its intersection with the $x$ axis indicates a starting date of major rift opening around 1992.

\subsection{Evolution of the rifting area on Mertz Glacier Tongue since 1996}

To follow the evolution of these rifts, we first derived the area of both rifts (Fig. 5), for the period 1996-2009, using ERS (first epoch in 1996) and Landsat 7 images. Several things can affect an individual measurement (e.g. sun orientation, shadowing effects, spatial resolution of the images, user interpretation). Measurements repeated a few times by two independent users obtained very similar results. We indicate the precision of our measurements as two pixels on each side of the rift, equating to $\pm 30 \mathrm{~m}$ of rift width or $\pm 0.5 \mathrm{~km}^{2}$ of area, as represented by the vertical bars in Figure 5.

The evolution of the rift area comprises two main stages. Up to 2002, the eastern rift area increased as the rift widened, and lengthened as the tip propagated west. Then, during 2002, the western rift (blue lines in Fig. 5) started to open. From 2003, the eastern rift started closing while the western rift continued to develop. We estimate an effective total rift width as the sum of the two areas divided by the Mertz Glacier Tongue width, which amounts to $\sim 350$ m from 2003 onwards. The linear fit of the sum over the entire period gives an opening rate of $\sim 0.91 \mathrm{~km}^{2} \mathrm{a}^{-1}$ in area, $60 \mathrm{~m} \mathrm{a}^{-1}$ in width, or $16 \mathrm{~cm} \mathrm{~d}^{-1}$, which is comparable with the western rift opening rate of $12 \mathrm{~cm} \mathrm{~d}^{-1}$ measured by the GPS stations at one section across the rift in 2007-08. Extrapolating back to zero area gives an approximate start date for the eastern rift opening $\sim 1992$. The 2002 initiation of the western rift is coincident with the impact of the C08 iceberg on Mertz Glacier Tongue (Massom and others, 2015). These two rifts can be defined as continuously active (C.C. Walker and others, 2013), as their evolution did not stop after their initiation and has not shown any dormant period.

\subsection{Differential motion across the rift}

In Figure 6, we present time series of the across-tongue component of the tidal current calculated from the TUGO$\mathrm{M}$ barotropic model (with European Centre for MediumRange Weather Forecasts (ECMWF) atmospheric forcing) (Mayet and others, 2013), and of the across-tongue $(y)$ 

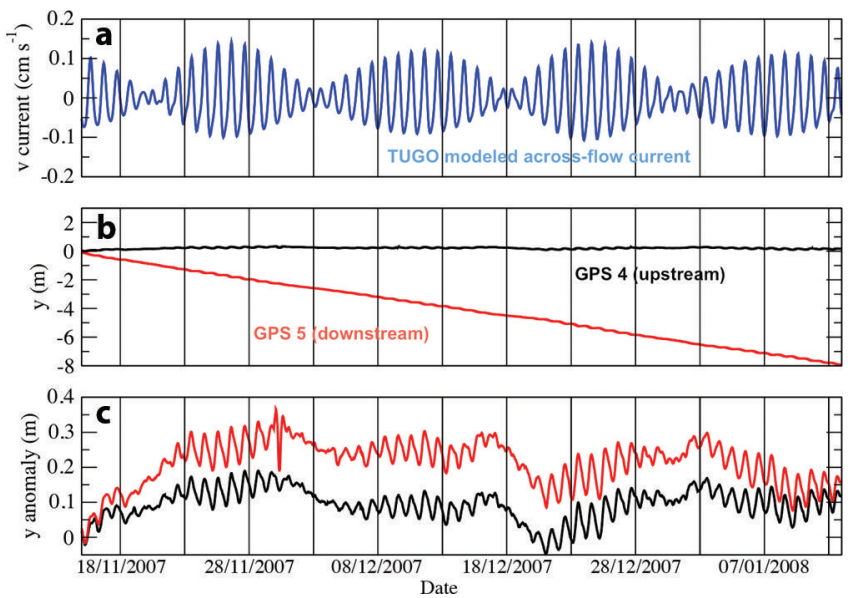

Fig. 6. Time series of the mean velocity of (a) the TUGO modeled across-tongue current and (b) across-tongue position (black for GPS 4 (upstream), red for GPS 5 (downstream)), with the mean velocity of GPS 4 removed from both time series in order to show the $8 \mathrm{~m}$ opening of the rift over 60 days. We clearly see that positive (negative), across-tongue ocean forces correspond to a westward (eastward) displacement of the ice tongue. (c) Across-tongue position anomaly with mean velocity of GPS 4 removed from the GPS 4 time series (red for GPS 5) to show finer-scale across-tongue motion. Date format is $\mathrm{dd} / \mathrm{mm} /$ yyyy.

component of positions measured at GPS 4 (black) and GPS 5 (red). Positive (negative) values of the across-tongue current correspond to westward (eastward) currents. Here we use the current as a proxy for the across-tongue components of the three forces associated with ocean circulation that act on the ice tongue (the pressure force, the drag force and the sea-surface slope-induced gravity force) as they all act in phase. Although the slope-induced force is not strictly linearly related to the current, it is qualitatively well represented by it (Mayet and others, 2013).

The paths of GPS 4 and GPS 5 evolve into different directions over time. The mean velocity vector of GPS 5 is rotated $35^{\circ}$ to the east of the mean velocity vector of GPS 4. This difference in direction is a consequence of the rift opening. Over 60 days, we measured a rift opening of $8 \mathrm{~m}$ (Fig. 6b) or a mean rate of $12 \mathrm{~cm} \mathrm{~d}^{-1}$.

Station GPS 5 is located on the downstream, less constrained part of the ice tongue, and exhibits larger variability in the movement of this downstream part of Mertz Glacier Tongue. The time of the maximum in the tidal current matches the maximum displacement in GPS position. The greatest amplitudes of across-tongue movement occur during spring tides. The daily tidal modulation of the opening of the rift is $\sim 5 \mathrm{~cm}$ in amplitude, almost half the daily rate of opening. Considering these observations, we deduce that ocean currents are a major factor driving the rifting processes in the case of Mertz Glacier Tongue and we assume that rift propagation is continuous since its initiation (C.C. Walker and others, 2013).

We computed the changes in the relative vector between GPS 4 and GPS 5 as a function of time and resolved these changes into along-tongue and across-tongue components. We then subtract the mean trend from each component and filter out variations with periods 4 days to produce two time series of residuals (Fig. 7). The 4 day filter eliminates the daily-scale tidal variations. We note there is a systematic smooth variation with time in the residuals represented by
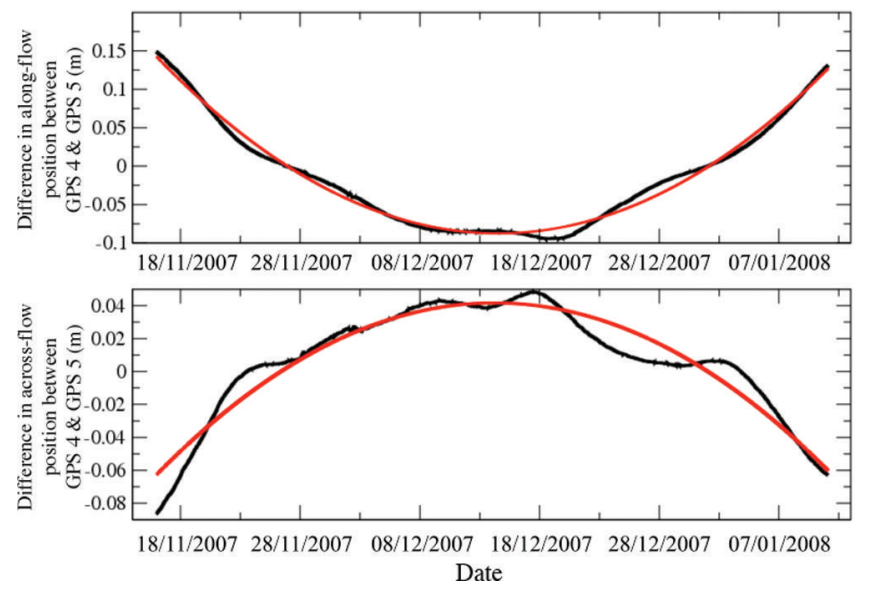

Fig. 7. Relative along-tongue and across-tongue displacements of the relative vector between GPS 4 and GPS 5 over 60 days. The black curves are filtered for periods shorter than 3 days with a linear filter, and in red appears the parabolic fit for the 60 days. The difference given relative to GPS 4 shows that, along-tongue, GPS 5 approaches GPS 4 and then comes back to its position. For the across-tongue movement, GPS 5 is located on the western side (negative) of GPS 4 and then moves to the eastern side (positive) of GPS 4. This movement is the result of a rotation of GPS 5 relative to GPS 4. Its center of rotation is calculated using the parabolic fit and is shown in Figure 2. Date format is $\mathrm{dd} / \mathrm{mm} / \mathrm{yyyy}$.

the red curves. This smooth variation in rate is explained by a rotation of the downstream part of the tongue about a center $15.7 \mathrm{~km}$ from the midpoint of the vector as shown in Figure 2. Given this rotation, the expected pattern of residuals is shown as the red curve in Figure 7. The deviations of the filtered observations (black curve) from those for steady rotation (red curve) in Figure 7 indicate that this relative movement is not strictly a simple rotation and the center of the rotation may not be at a single point but may shift over time within the active rift area. In the longer term, the behavior of this part of the ice tongue is thought to be changing as the stresses evolve, as indicated by the earlier behavior of this 'rifting system'. This showed us that the rift opening is not linear and the evolution of the stresses induced by its opening (implying the changing of the bending moment on the remaining ice tongue) influences the interaction of the ice tongue with the currents, and hence its effect on the rifting.

Even if the rifting area was increasing over time and we anticipated that the tongue was going to calve, we would not be able to forecast the date of any calving event. In fact, the opening of the rifts is not linear, and unforeseen events (e.g. iceberg collisions) can completely change the balance of stresses on the ice tongue (Massom and others, 2015). This effect is not new and has been studied in the past (Holdsworth, 1985), but we still observe that the forces associated with tidal circulation are strong enough to open the rift through a bending moment on the ice tongue. They tend to increase its area and thus represent factors to take into account when investigating calving processes of ice tongues.

\subsection{Impact of tides on the ice flow velocity: change in behavior}

From the study of Legresy and others (2004), we expected to see a modulation of the flow velocity dependent on the direction of the tidal current. However, the evolution of Mertz Glacier Tongue induced a change in this modulation. 
In this subsection, we investigate the effect of oceanic circulation on the rift opening, comparing the two sequences (before 2000 and after 2007) as well as the tidal modulation of the flow velocity using the Gudmundsson (2007)-based model.

Using our 60 day GPS time series, we computed the along-tongue ice speed by a simple linear fit on the positions within time windows of different lengths. We also computed various statistics of the velocity estimates using standard statistical tests, such as a Student's $t$ test. We find that using a time window wider than 30 min gives reliable estimates of the speed, which are significant at the $98 \%$ confidence interval. Calculating the linear fit over different time windows gives an idea of the part of the signal that is not related to the noise or to any kind of non-modeled signal (in that case, under $30 \mathrm{~min}$ sampling). Table 1 presents the velocity variability computed for the whole 60 day record, the associated $98 \%$ confidence interval, and the correlation with the model for different widths of the time window.

In Figure 8a, we see that the speeds computed from the measured GPS positions with a 4 hour window show a tidal pattern with daily peaks, together with a fortnightly modulation from the lunar-solar cycle, confirmed by a harmonic analysis. Figure $8 \mathrm{~b}$ and $\mathrm{c}$ show a shorter time interval of the same time series over two 4 day intervals at spring tide and neap tide phase respectively. In addition, we display the speed computed with a 1 hour time window. At this short sub-tidal timescale, there is a clear and strong variability in the velocity, with positive and negative peaks occurring at any time over the series, whether during spring or neap tides. But there does appear to be a pattern in the association of peaks in the velocity and phases of the tides. In the spring tide phase, the greatest maxima occur during the ascending phases of the tides, and the maxima increase in value as the tide rises. During neap tide, the sub-tidal variability appears to be spread more evenly through the day, although there does appear to be a weak association of
Table 1. Computed variability from the GPS 4 along-tongue velocity calculated over 60 days and for different time windows, the associated confidence interval, the variance of the confidence and the correlation with the model

\begin{tabular}{lcccc}
\hline $\begin{array}{l}\text { Time } \\
\text { window } \\
\begin{array}{l}\text { for velocity } \\
\text { estimation }\end{array}\end{array}$ & $\begin{array}{c}\text { RMS } \\
\text { variability } \\
\text { on velocity } \\
\text { time series }\end{array}$ & $\begin{array}{c}\text { Mean } \\
\text { uncertainty } \\
\text { estimates }\end{array}$ & $\begin{array}{c}\text { RMS } \\
\text { variability on } \\
\text { uncertainty }\end{array}$ & $\begin{array}{c}\text { Correlation } \\
\text { between GPS } \\
\text { measured velocity } \\
\text { and model } \\
\text { (sea-surface height } \\
\text { and slope) }\end{array}$ \\
& $\mathrm{m} \mathrm{d}^{-1}$ & $\mathrm{~m} \mathrm{~d}^{-1}$ & $\mathrm{~m} \mathrm{~d}^{-1}$ & \\
\hline 1 hour & 0.218 & 0.094 & 0.087 & 0.213 \\
2 hours & 0.132 & 0.038 & 0.033 & 0.348 \\
4 hours & 0.087 & 0.015 & 0.012 & 0.513 \\
6 hours & 0.072 & 0.009 & 0.007 & 0.585 \\
\hline
\end{tabular}

strongest maxima with the bottom of the tidal range. The peak-to-peak amplitude of velocity variations at sub-tidal scales can reach $1.5 \mathrm{~m} \mathrm{~d}^{-1}$ or $\sim 50 \%$ of the average longterm velocity. Figure $8 \mathrm{~d}$ shows the velocity recorded at GPS 4 (green) and GPS 5 (blue). The mean along-tongue velocity calculated for GPS 5 is slightly larger than for GPS 4 and is likely a consequence of the effect of longitudinal extension of the floating tongue together with the opening of the rift.

Figure 9 shows the velocity in the along-tongue direction as measured at GPS 4 (upstream of the rift), the height measured at the same station, and the sea-surface slope (along-tongue), as calculated from the TUGO-M model (which incorporates the atmospheric pressure, wind and tides with ECMWF 3 hour forcing). We first notice that the sea-surface height measured in the area is characterized by a spring to neap cycle with a strong fortnightly period. The amplitude of the semidiurnal component varies over each
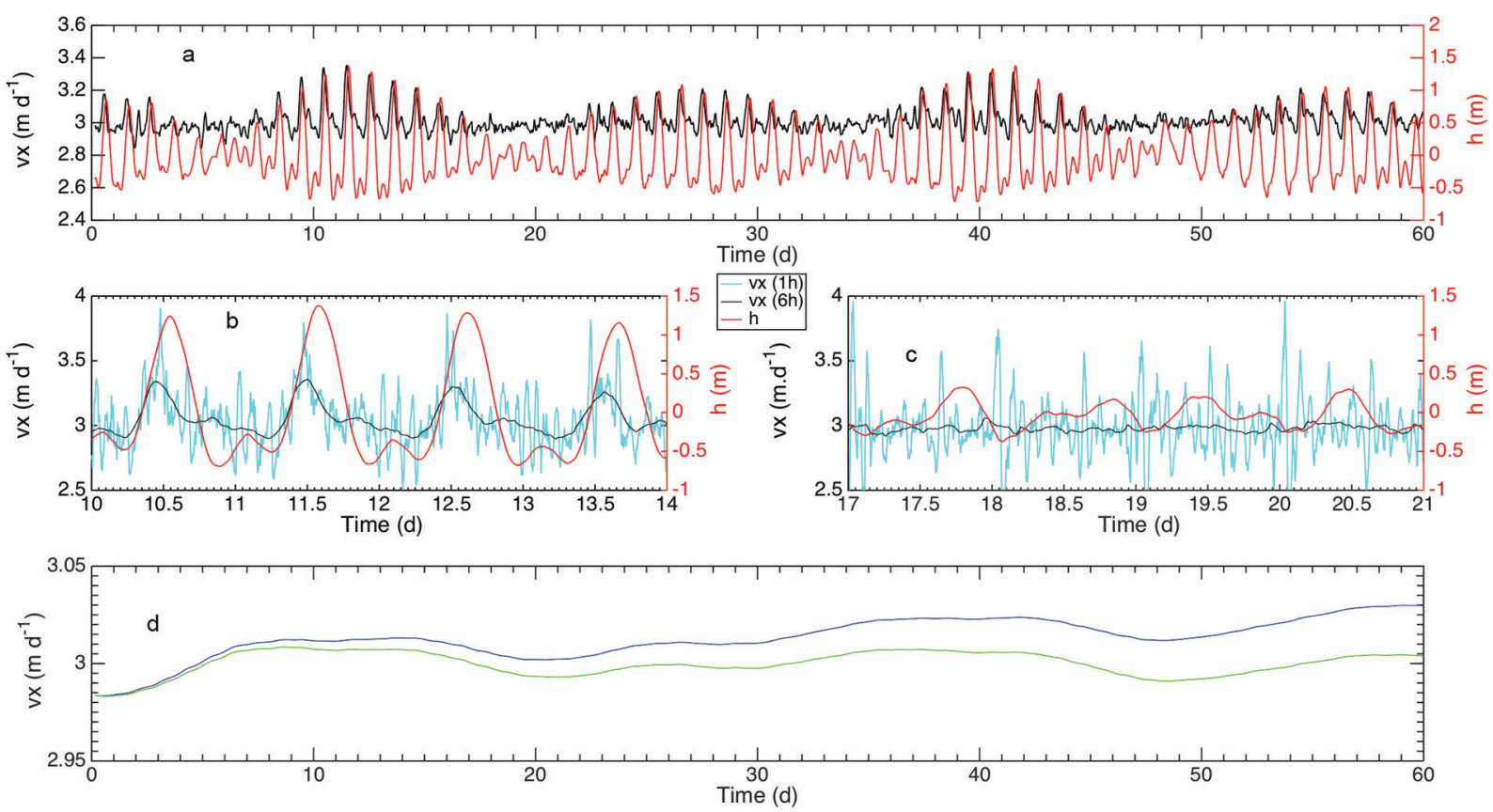

Fig. 8. (a) Along-tongue velocity (black) and sea-surface height measured at GPS 4 (red) over 60 days. (b, c) Along-tongue velocity and seasurface height calculated from 1 hour (blue) and 4 hour time windows (black) for spring tides (b) and for neap tides (c) over 4 day intervals. (d) Comparison between GPS 4 (green) and GPS 5 (blue) along-tongue velocity. 


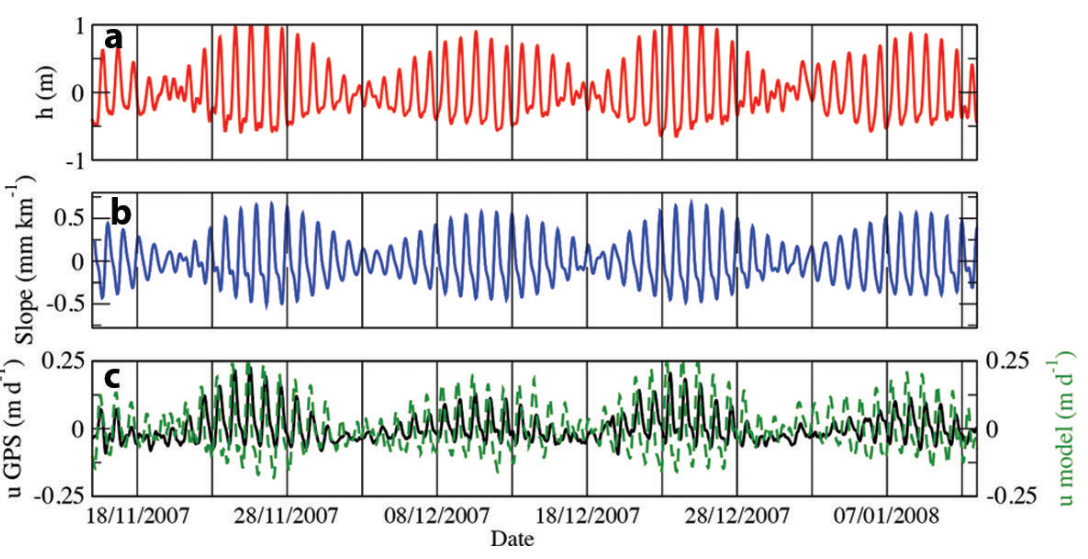

Fig. 9. (a) Sea-surface height anomaly; (b) sea-surface slope computed from TUGO-M; and (c) along-tongue velocity as recorded at GPS 4 (black) and along-tongue velocity modeled using the sea-surface height and slope (green) over 60 days.

period, with large semidiurnal amplitudes associated with the interval (neap to spring) corresponding to the increase in the fortnightly component, and small semidiurnal amplitudes corresponding to the decrease from spring to neap phase. Secondly, we see apparent daily and fortnightly variations of the ice velocity at GPS 4. The amplitude envelope of the along-tongue component is proportional to the envelope of the spring tide cycle. The mean velocity is $3.01 \mathrm{~m} \mathrm{~d}^{-1}$ with a range of typical values from 2.95 up to $3.35 \mathrm{~m} \mathrm{~d}^{-1}$. The correlation coefficient of the ice velocity with the sea-surface height is $\sim 0.6$.

The sea-surface slope signal has the same general characteristics as the sea-surface height signal. However, the phasing is significantly different, even though the variation of sea-surface height and the sea-surface slope are similar in character. The variations of surface elevation closely match those of the ice-shelf along-tongue displacement in both relative amplitude and phase, suggesting that tidally driven sea-surface height is the primary driver of alongtongue displacement. The maximum peak in ice velocity occurs 2.5 hours after the maximum peak in tidal elevation. On the other hand, the timing of the peak in sea-surface slope matches the peak of the semidiurnal tidal velocity.

The Legresy and others' (2004) study of ice velocity modulation on Mertz Glacier Tongue showed that the
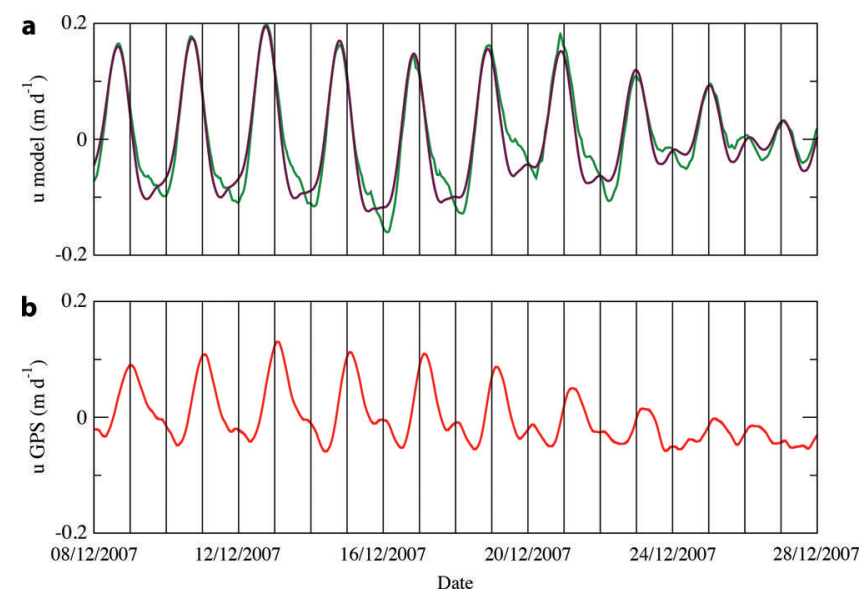

Fig. 10. (a) Zoom-in of the modeled velocity (purple) from the seasurface height only, and along-tongue velocity modeled using the sea-surface height and the slope (green) over 2 days. (b) Alongtongue velocity from GPS 4 observed (red). direction of tidal circulation and the effect of drag on the walls of the fjord were the main drivers of the flow modulation. The present study identifies a completely different behavior, where we find a small range of ice velocity variation, $1075-1225 \mathrm{ma}^{-1}$, in 2007, compared with the very large range of $700-2400 \mathrm{~m} \mathrm{a}^{-1}$ in 2000 . The main change that has occurred over the 7 years between these dates is the opening of the rifts, which has modified the bending moment of the ice tongue, and disrupted transmission of the lateral load onto the walls of the fjord.

We now use our basal shear stress based model (Section 2.3) with a selection of scenarios to generate time series of along-tongue velocity values. We compare results from two of these scenarios (green and purple in Fig. 10) with our directly measured velocities (red in Fig. 10). We then discuss the effects involved in the modulation of the along-tongue velocity. For this analysis, we assume that the basal stress on the ice tongue is zero and, in particular, that there is no drag from the sides of the fjord on the floating part of the system within the fjord. Therefore velocity variations at any point downstream of the grounding line will be the same as those at the grounding line. Here we present results from GPS 4 (GPS 5 being the same).

The measured and modeled velocities are presented in Figure 10 as anomalies with respect to the long-term mean values. The comparison shows that despite the model simplicity, it reproduces fortnightly variations in velocity in considerable detail and gives a good fit to the amplitude of the variations. The model explains the main part of the velocity variation recorded by the GPS with a correlation coefficient of 0.69 . The different drivers in the model, i.e. the sea-surface height and sea-surface slope, both derived from TUGO-M, contribute at different levels. With seasurface height as the only driver, the model explains $43 \%$ of the variance, and the addition of the sea-surface slope explains a further $4 \%$ of the variance. The addition of atmospheric forcing through the contribution of pressure and wind does not make a significant difference to the computed velocities. In other words, the atmospheric forcing does not affect the velocities at the frequencies in the velocity time series where we observe the main variability. The tidal effects are thus the primary drivers. The modeled velocities shown for a short time interval in Figure 10 are derived using only the sea-surface height term (purple), and using both the sea-surface height and slope (green). 


\section{DISCUSSION}

Of the potential mechanisms driving diurnal and semidiurnal horizontal ice-shelf displacements, it appears that seasurface height and sea-surface slope dominate, with the ice tongue responding elastically over these tidal periods. The along-tongue velocity signal (Fig. 8) is mainly explained by modulation from these tidal contributions, but a large part of the variance related to higher-frequency (sub-tidal) contributions remains in the signal (Table 1). Comparison of the modeled and observed velocity time series shown in Figures 9 and 10 highlights two differences between the model and real-world situations. Firstly, there is a small but significant phase difference such that the observed velocities lag the model values by $\sim 2-3$ hours. This lag is indicative of there being other influences acting on the system, and/or more complex interaction between the tidal drivers and the glacier than is represented in our model. Secondly, the envelope of velocity variations is asymmetric about the mean but more accentuated in the observed velocities, such that the envelope appears truncated at lower values. Note that the observed velocity time series shown in Figures 9 and 10 has been filtered to highlight the tidal signal and remove the sub-tidal contributions.

The lack of GPS sites distributed along Mertz Glacier Tongue to observe sea-surface height variation prevents us from directly resolving any differential amplitude motion of the ice tongue induced by sea-surface slope. On the Ronne Ice Shelf, Makinson and others (2012) observed an amplified motion such that the ice-shelf compression or elongation is accentuated towards the front. In regions with small tidal amplitudes, we expect the horizontal oscillations will be quite small.

Figure 8 shows there is a larger variability of the velocity at sub-tidal scales during the ascending phase of the tides, which could be related to lubrication of subglacial sediments. At low tide, the sub-tidal signal seen in the observed velocity variation suggests the involvement of mechanism(s) acting on the glacier specifically at low tides. Our findings thus indicate that the mechanisms acting on the ice tongue in response to the tides are more complex than currently implemented in our model. The various processes, including opening and closing of crevasses, flexure of the ice tongue, basal and lateral drag, lubrication, till coupling, etc., represent factors inducing a nonlinear response of the glacier system (Anandakrishnan and others, 2007; R.T. Walker and others, 2012, 2013). In order to reproduce the observed velocity modulations more precisely, we need a much more complex model, as well as a much broader investigation of conditions beneath the glacier, at the grounding line and around the sides of the fjord.

Following Legresy and others (2004) and Doake and others (2002) we attempted to integrate the effect of tidal currents in the across-tongue direction. We used the acrosstongue displacement of Mertz Glacier Tongue to modify the retarding stress and thus obtain the impact of the tidal current direction on the ice tongue velocity. We implemented the modified Gudmundsson model but found the across-tongue variations to be uncorrelated with the alongtongue velocity variations (not shown here). This mechanism, involving the east-west flexure of the tongue, had previously exerted a significant effect in 2000 (causing the along-tongue velocity to vary by a factor of three) but it no longer seems to exert an influence on the system in 2007. We infer that the opening of the rift has led to a decoupling of the section of the tongue upstream of the rift from the bending moment of the downstream section of the ice tongue, so the influence of the across-tongue tidal circulation is no longer transmitted into the fjord where it used to induce large decreases in velocity.

\section{CONCLUSION}

In studying Mertz Glacier, we have used data collected by two in situ surveys. The work of Legresy and others (2004) included three days of GPS measurements spread over 4 days in 2000 near the tip of Mertz Glacier Tongue. During 2007, GPS data were collected continuously over 60 days across an active rift approximately midway along Mertz Glacier Tongue. These data have allowed us to view Mertz Glacier Tongue under, primarily, a bending regime (in 2000) and then under rifting behavior (in 2007), giving us insight into an ice tongue operating under different mechanical conditions. In both surveys, we captured the basic flow of Mertz Glacier Tongue. The combination of the two surveys, however, has allowed us to analyze the variable forces acting on Mertz Glacier Tongue driven by tides, atmospheric pressure, sea-surface height and sea-surface slope, and bed-shape/wall friction.

The difference in dynamic behavior of the ice tongue in 2007 compared with that in 2000 is the result of the rift opening, and perhaps an increase in length. In 2000, the bending of the ice tongue modulated the drag caused by contact of the eastern flank of the ice tongue with the wall of the fjord, which influenced the ice tongue velocity. From 2002 onwards, the second rift opening on the western side inhibited the transmission of the bending moment to the upstream part of the ice tongue. The forces exerted by the tidal circulation then contributed to opening the rift and rotating the downstream part of the ice tongue. To examine this theory, we used a model in which the basal sliding velocity is expected to be some function of basal shear stress (Gudmundsson, 2007). We implemented the effects of seasurface height and sea-surface slope as being the main drivers of the ice tongue velocity modulation. For Mertz Glacier Tongue, this conceptually simple model reproduced fortnightly variations of velocity well, and in considerable detail. The sea-surface height appears to be the main driver of the variation in ice velocity, but inclusion of the seasurface slope adds $\sim 5 \%$ more information to the model. Furthermore, we concluded that the across-tongue forces do not appear to have a significant impact anymore, contrary to the case during 2000.

The effect of sea-surface slope represents a newly observed ice-shelf forcing term and once again highlights the complicated nonlinear response of tidal forcing, which includes basal shear stress under the grounded ice, and lateral shear stress in the fjords. A comprehensive understanding of these systems is important to identify key processes, their interaction and their parameterization in models. Understanding the dynamics of ice shelves and how they respond to the full spectrum of ocean forcing, primarily through ocean tides, is fundamental to understanding their coupling to, and influence on, ice streams and the ice sheet.

One aspect to take into account when looking at rift propagation and ice-shelf stability is the thermodynamical interaction between ice and ocean. This study focused on the mechanical aspect of this interaction, but as noted in 
various publications on the Amundsen Sea sector (MacGregor and others, 2012), a major effect acting on ice-shelf retreat is sub-ice shelf thinning leading to disintegration (Jacobs and others, 2011). Finally, the composition of rifts with ice melange is a factor requiring consideration when investigating rift propagation (Kulessa and others, 2014).

This study has put into perspective the complexity of processes modulating the Mertz Glacier ice tongue velocity, and advances the identification of factors influencing the evolution of an ice tongue and related outlet glacier dynamics. The length of an ice tongue, its bending moment and the development of rifts are able to modify the overall behavior of an ice stream, and need to be considered in the context of actual changes in mass balance and sea-level rise. In other words, using the single example of the Mertz Glacier behavior, we are not able to generate a general law sufficient to explain its behavior through time. Furthermore, it is clear that any kind of general calving law might be applied to every ice tongue in Antarctica and/or Greenland and this fact needs to be considered in current work on future predictions.

\section{ACKNOWLEDGEMENTS}

This study is part of the CRAC-ICE project, supported by the CNES (Centre National d'Etudes Spatiales, France), ANR (Agence Nationale de la Recherche, France) DACOTA grant, the IPEV (Institut Polaire Paul-Emile Victor, France), CNRS/INSU (Centre National de la Recherche Scientifique/ Institut National des Sciences de I'Univers, France) and the University of Tasmania. Part of this research was also supported by an Australian Research Council Discovery grant (DP0666733) awarded to Richard Coleman and was undertaken in the Antarctic Climate \& Ecosystems Cooperative Research Centre, supported by the Australian Government's Cooperative Research Centres Program. We thank the Master and crew of MV L'Astrolabe and helicopters for their assistance in the deployment of the GPS stations on Mertz Glacier Tongue and the retrieval of the GPS data.

\section{REFERENCES}

Anandakrishnan S and Alley RB (1997) Stagnation of ice stream C, West Antarctica by water piracy. Geophys. Res. Lett., 24(3), 265-268 (doi: 10.1029/96GL0416)

Anandakrishnan S, Alley RB and Waddington ED (1994) Sensitivity of the ice-divide position in Greenland to climate change. Geophys. Res. Lett., 21(6), 441-444 (doi: 10.1029/94GL00094)

Anandakrishnan S, Catania GA, Alley RB and Horgan HJ (2007) Discovery of till deposition at the grounding line of Whillans Ice Stream. Science, 315(5820), 1835-1838 (doi: 10.1126/science. 1138393)

Bindschadler RA, King MA, Alley RB, Anandakrishnan S and Padman L (2003) Tidally controlled stick-slip discharge of a West Antarctic ice stream. Science, 301(5636), 1087-1089 (doi: 10.1126/science.1087231)

Blewitt G (2008) Fixed point theorems of GPS carrier phase ambiguity resolution and their application to massive network processing: Ambizap. J. Geophys. Res. Solid Earth, 113(B12), B12410 (doi: 10.1029/2008JB005736)

Brunt KM, King MA, Fricker HA and MacAyeal DR (2010) Flow of the Ross Ice Shelf, Antarctica, is modulated by the ocean tide. J. Glaciol., 56(195), 157-161 (doi: 10.3189/ 002214310791190875)
Catania GA, Conway H, Raymond CF and Scambos TA (2006) Evidence for floatation or near floatation in the mouth of Kamb Ice Stream, West Antarctica, prior to stagnation. J. Geophys. Res. Earth Surf., 111(F1), F01005 (doi: 10.1029/ 2005JF000355)

Clarke GKC (1987) Subglacial till: a physical framework for its properties and processes. J. Geophys. Res. Solid Earth, 92(B9), 9023-9036 (doi: 10.1029/JB092iB09p09023)

De Angelis H and Skvarca P (2003) Glacier surge after ice shelf collapse. Science, 299(5612), 1560-1562 (doi: 10.1126/ science.1077987)

Doake, CSM and 6 others (2002) Tide-induced lateral movement of Brunt Ice Shelf, Antarctica. Geophys. Res. Lett., 29(8), 1226-1229 (doi: 10.1029/2001GL014606)

Echelmeyer KA, Harrison WD, Larsen C and Mitchell JE (1994) The role of the margins in the dynamics of an active ice stream. J. Glaciol., 40(136), 527-538

Fischer UH, Porter PR, Schuler T, Evans AJ and Gudmundsson GH (2001) Hydraulic and mechanical properties of glacial sediments beneath Unteraargletscher, Switzerland: implications for glacier basal motion. Hydrol. Process., 15(18), 3525-3540 (doi: 10.1002/hyp349)

Frezzotti M, Cimbelli A and Ferrigno JG (1998) Ice-front change and iceberg behaviour along Oates and George V Coasts, Antarctica, 1912-96. Ann. Glaciol., 27, 643-650

Gudmundsson GH (2006) Fortnightly variation in the flow velocity of Rutford Ice Stream, West Antarctica. Nature, 444, 1063-1064 (doi: 10.1038/nature05430)

Gudmundsson GH (2007) Tides and flow of Rutford Ice Stream, West Antarctica. J. Geophys. Res. Earth Surf., 112(F4) F04007 (doi: 10.1029/2006JF000731)

Gudmundsson GH (2011) Ice-stream response to ocean tides and the form of the basal sliding law. Cryosphere, 5(1), 259-270 (doi: 10.5194/tc-5-259-2011)

Holdsworth G (1985) Some effects of ocean currents and wave motion on the dynamics of floating glacier tongues. In Jacobs SS ed. Oceanology of the Antarctic continental shelf. (Antarctic Research Series 43) American Geophysical Union, Washington, DC, 253-271 (doi: 10.1029/AR043p0253)

Iverson NR, Hanson B, Hooke RLeB and Jansson P (1995) Flow mechanism of glaciers on soft beds. Science, 267(5194), 80-81 (doi: 10.1126/science.267.5194.80)

Jacobs SS, Jenkins A, Giulivi CF and Dutrieux P (2011) Stronger ocean circulation and increased melting under Pine Island Glacier ice shelf. Nature Geosci., 4, 519-523 (doi: 10.1038/ ngeo1188)

Keys J and Fowler D (1989) Sources and movement of icebergs in the south-west Ross Sea, Antarctica. Ann. Glaciol., 12, 85-88

Khazendar A, Rignot E and Larour E (2007) Larsen B Ice Shelf rheology preceding its disintegration inferred by a control method. Geophys. Res. Lett., 34(19), L19503 (doi: 10.1029/ 2007GL030980)

King MA, Makinson K and Gudmundsson GH (2010) Nonlinear interaction between ocean tides and the Larsen C Ice Shelf system. Geophys. Res. Lett., 38(8), L08501 (doi: 10.1029/ 2011GL046680)

King MA and 6 others (2011) Ocean tides in the Weddell Sea: new observations on the Filchner-Ronne and Larsen C ice shelves and model validation. J. Geophys. Res., 116(C6), C06006 (doi: 10.1029/2011JC006949, 20)

Kulessa B, Jansen D, Luckman AJ, King EC and Sammonds PR (2014) Marine ice regulates the future stability of a large Antarctic ice shelf. Nature Comm., 5, 3707 (doi: 10.1038/ncomms4707)

Legresy B, Wendt A, Tabacco I, Remy F and Dietrich R (2004) Influence of tides and tidal current on Mertz Glacier, Antarctica. J. Glaciol., 50(170), 427-435 (doi: 10.3189/ 172756504781829828)

Lescarmontier L, Legresy B, Coleman R, Perosanz F, Mayet C and Testut L (2012) Vibration of the Mertz Glacier ice tongue. J. Glaciol., 58(210), 665-676 (doi: 10.3189/2012JoG11J089) 
MacAyeal DR, Rignot E and Hulbe CL (1998) Ice-shelf dynamics near the front of the Filchner-Ronne Ice Shelf, Antarctica, revealed by SAR interferometry: model/interferogram comparison. J. Glaciol, 44(147), 419-428

MacGregor JA, Catania GA, Markowski MS and Andrews AG (2012) Widespread rifting and retreat of ice-shelf margins in the eastern Amundsen Sea Embayment between 1972 and 2011. J. Glaciol., 58(209), 458-466 (doi: 10.3189/2012JoG11J262)

Makinson K, King MA, Nicholls KW and Gudmundsson GH (2012) Diurnal and semidiurnal tide-induced lateral movement of Ronne Ice Shelf, Antarctica. Geophys. Res. Lett., 39(10), L10501 (doi: 10.1029/2012GL051936)

Marty JC and 10 others (2012) GINS: The CNES-GRGS GNSS Scientific software. In 3rd International Colloquium Scientific and Fundamental Aspects of the Galileo Programme, ESA Proceedings WPP326 (Vol. 31)

Massom RA and 7 others (2015) External influences on the Mertz Glacier Tongue (East Antarctica) in the decade leading up to its calving in 2010. J. Geophys. Res. Earth Surf., 120(3), 490-506 (doi: 10.1002/2014JF003223)

Mayet C, Testut L, Legresy B, Lescarmontier L and Lyard F (2013) High-resolution barotropic modeling and the calving of the Mertz Glacier, East Antarctica. J. Geophys. Res. Oceans, 118(10), 5267-5279 (doi: 10.1002/jgrc.20339)

Murray T, Smith AM, King MA and Weedon GP (2007) Ice flow modulated by tides at up to annual periods at Rutford Ice Stream, West Antarctica. Geophys. Res. Lett., 34(18), L18503 (doi: 10.1029/2007GL031207)

Paterson WSB (1994) The physics of glaciers, 3rd edn. Elsevier, Oxford

Rignot E, Casassa G, Gogineni P, Krabill W, Rivera A and Thomas R (2004) Accelerated ice discharge from the Antarctic Peninsula following the collapse of Larsen B ice shelf. Geophys. Res. Lett., 31(18), L18401 (doi: 10.1029/2004GL020697)
Scambos TA, Bohlander JA, Shuman CA and Skvarca P (2004) Glacier acceleration and thinning after ice shelf collapse in the Larsen B embayment, Antarctica. Geophys. Res. Lett., 31(18), L18402 (doi: 10.1029/2004GL020670)

Thomas RH (2007) Tide-induced perturbations of glacier velocities. Global Planet. Change, 59(1-4), 217-224 (doi: 10.1016/ j.gloplacha.2006.11.017)

Truffer M (1999) Till deformation beneath Black Rapids Glacier, Alaska and its implication on glacier motion. (PhD thesis, University of Alaska Fairbanks)

Tulaczyk S (2006) Scale independence of till rheology. J. Glaciol., 52(178), 377-380 (doi: 10.3189/172756506781828601)

Tulaczyk S, Kamb WB and Engelhardt HF (2000) Basal mechanics of Ice Stream B, West Antarctica. 1. Till mechanics. J. Geophys. Res. Solid Earth, 105(B1), 463-481 (doi: 10.1029/1999JB900329)

Walker CC, Bassis JN, Fricker HA and Czerwinski RJ (2013) Structural and environmental controls on Antarctic ice shelf rift propagation inferred from satellite monitoring. J. Geophys. Res. Earth Surf., 118(4), 2354-2364 (doi: 10.1002/2013JF002742, 2013)

Walker RT, Christianson K, Parizek BR, Anandakrishnan S and Alley RB (2012) A viscoelastic flowline model applied to tidal forcing of Bindschadler Ice Stream, West Antarctica. Earth Planet. Sci. Lett., 319-320, 128-132 (doi: 10.1016/j.epsl.2011.12.019)

Walker RT, Parizek BR, Alley RB, Anandakrishnan S, Riverman KL and Christianson K (2013) Ice-shelf tidal flexure and subglacial pressure variations. Earth Planet. Sci. Lett., 361, 422-428 (doi: 10.1016/j.epsl.2012.11.008)

Winberry JP, Anandakrishnan S, Wiens DA, Alley RB and Christianson K (2011) Dynamics of stick-slip motion, Whillans Ice Stream, Antarctica. Earth Planet. Sci. Lett., 305(3-4), 283-289 (doi: 10.1016/j.epsl.2011.02.052)

Young N, Legresy B, Coleman R and Massom R (2010) Mertz Glacier Tongue unhinged by Giant Iceberg. Austral. Antarct. Mag., 18, 19 